\title{
Germanium doping for improved silicon substrates and devices
}

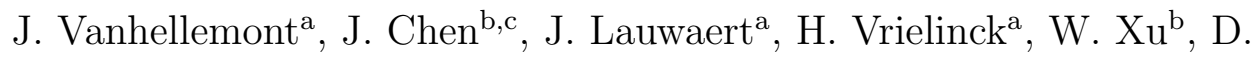 \\ Yang $^{\mathrm{b}}$, J.M. Rafíd ${ }^{\text {, H. Ohyama }}{ }^{\mathrm{e}}$, E. Simoen ${ }^{\mathrm{f}}$ \\ ${ }^{a}$ Department of Solid State Sciences, Ghent University, Krijgslaan 281-S1, B-9000 \\ Ghent, Belgium \\ ${ }^{b}$ State Key Laboratory of Silicon Materials, Zhejiang University, 310027 Hangzhou, P.R. \\ China \\ ${ }^{c}$ Currently at Institut für Angewandte Physik, Technische Universität Dresden, Professur \\ für Halbleiterphysik, D-01062 Dresden, Germany \\ ${ }^{d}$ Centro Nacional de Microelectronica (CNM-CSIC), Campus U.A.B, 08193, Bellaterra \\ Barcelona, Spain \\ ${ }^{e}$ Kumamoto National College of Technology, 2659-2 Suya Koshi Kumamoto, 861-1102 \\ Japan \\ ${ }^{f}$ IMEC, Kapeldreef 75, B-3001 Leuven, Belgium
}

\begin{abstract}
During the last decade, the $300 \mathrm{~mm}$ silicon wafer has been optimized and one is studying the move to $450 \mathrm{~mm}$ crystals and wafers. The ever increasing silicon crystal diameter leads to two important trends with respect to substrate characteristics: the interstitial oxygen concentration decreases while the size of grown in voids (COP's) in vacancy-rich crystals is increasing.

The first effect is due to the large melt in which movements have to be controlled and partly suppressed by the use of magnetic fields. This magnetic confinement leads to a more uniform dopant incorporation but at the same time to a more limited transport of oxygen from the quartz crucible to the melt and the growing crystal. The reduced interstitial oxygen concentration and the lower thermal budget of modern device processing leads to strongly reduced oxygen precipitation and thus internal gettering capacity.

The increasing COP size (accompanied by a decreasing density) is caused by the decreasing pulling rate and thermal gradient that have to be used in order to avoid dislocation formation. The slower cooling of the crystal leads to a decreased void nucleation rate and at the same time to an increased thermal budget for void growth as well as a larger number of vacancies available per void.
\end{abstract}


In the present paper the effect of germanium doping in the range between $10^{16} \mathrm{~cm}^{-3}$ and $10^{19} \mathrm{~cm}^{-3}$ on COP formation and oxygen precipitation is discussed and illustrated. Also the beneficial effect of germanium doping with respect to wafer breakage during processing, with respect to the suppression of thermal donor formation and with respect to improving device radiation hardness is addressed.

Keywords:

Characterization A1, Defects A1, Czochralski method A2, Germanium

silicon alloys B1, Semiconducting silicon B2, Diodes B3

PACS: 61.72.J-, 61.72.Qq, 61.72.uf, 61.82.Fk, 85.30.Kk, 84.37.+q

\section{Introduction}

During the last decade the $300 \mathrm{~mm}$ silicon wafer has been optimized and one is already actively exploring the next size increase to $450 \mathrm{~mm}$. It is well known that with increasing crystal diameter, the interstitial oxygen concentration in the crystal is decreasing while the size of grown-in voids and thus also of the Crystal Originated Particles (COP's) observed on the wafer surface in vacancy-rich crystals is increasing, accompanied by a COP density decrease.

The first effect is related to the large melt in which movements have to be controlled and partly suppressed by the use of magnetic fields. The reduced melt movement leads to a more uniform dopant incorporation but at the same time to a more limited transport of oxygen from the quartz crucible to the melt and the crystal. The lower interstitial oxygen concentration in the silicon substrates and the reduced thermal budget of modern device processing lead to strongly reduced oxygen precipitation and thus also strongly reduced internal gettering capacity of the silicon substrates. In combination with the fact that modern wafers are two sided polished so that backside gettering of impurities is also no longer possible, this makes large diameter silicon wafers more vulnerable for metallic contamination.

The increasing COP size accompanied by a decreasing density is due to the decreasing pulling rate and thermal gradient in order to avoid dislocation formation. Due to the lower thermal gradient, the build-up of the vacancy supersaturation during cooling is slower leading to a lower void nucleation rate while at the same time the thermal budget for void growth controlled by vacancy diffusion is strongly increased as well as the number of vacancies 
available per void.

The standard approach to suppress void formation is by hot zone design in order to obtain the critical value of the ratio of the pulling rate over the thermal gradient predicted by the Voronkov theory [1], leading to an intrinsic point defect lean crystal so that no intrinsic point defect clustering occurs during crystal cooling, see e.g. [2] and references therein. A drawback of this approach is that the crystal pulling process window is rather narrow and imposes the use of magnetic fields already for $300 \mathrm{~mm}$ crystals.

Another, more recent approach to reduce not only the COP problem but also that of the reduced internal gettering capacity, is by doping the silicon crystal with a dopant that is not electrically active but that enhances oxygen precipitation and reduces at the same time the vacancy concentration available for void nucleation and growth. Nitrogen fulfills to a large extent these requirements and nitrogen doped $\mathrm{Cz}$ wafers are commercially available and used already on a relatively large scale.

In this respect, also Ge is a promising dopant and has the additional advantage that germanium is an isovalent impurity that can be alloyed with silicon over the whole composition range. Dislocation free Czochralski pulling of $\mathrm{Si}_{1-x} \mathrm{Ge}_{x}$ crystals is however limited to $\mathrm{x}$ values below a few percent although up to $15 \%$ has been demonstrated [3, 4]. Germanium doping has been reported to enhance interstitial oxygen precipitation and out-diffusion $[5,6]$, to suppress thermal donor (TDD) formation [7] and also to influence the COP density and size $[8,9,10]$.

Recently, Londos et al. [11, 12, 13] performed an extensive study of the influence of germanium doping on the behavior of oxygen and carbon impurity related complexes in electron irradiated silicon. Their observations were explained by assuming that for germanium concentrations below $10^{20} \mathrm{~cm}^{-3}$, germanium atoms act as temporary traps for vacancies and as such reduce the recombination rate of intrinsic point defects and Frenkel pairs. This leads to an increase of vacancy, self-interstitial, interstitial-oxygen and interstitialcarbon related defects like $\mathrm{VO}, \mathrm{C}_{i} \mathrm{O}_{i}, \mathrm{C}_{i} \mathrm{C}_{s}$ and $\mathrm{C}_{i} \mathrm{O}_{i}\left(\mathrm{Si}_{i}\right)$. For germanium doping above $10^{20} \mathrm{~cm}^{-3}$, an opposite behavior was however observed which was assumed to be due to the formation of germanium clusters acting as recombination centers for the intrinsic point defects. The described effects of germanium doping can have important consequences not only for radiation induced defect formation and population dynamics but also for defect formation during crystal pulling. Vacancy trapping by germanium atoms was also claimed by Chen et al. [14] based on density functional theory calculations 
although recent theoretical work of Chroneos et al. [15] suggests that the impact of germanium is negligible compared to vacancy clusters themselves acting as trap/sink for vacancies. Also recent quenching experiments [16] and a study with scanning infrared microscopy of voids in as-grown Czochralski silicon crystals with and without germanium doping [17], both revealed only a limited impact of germanium doping on the thermal equilibrium vacancy concentration at high temperatures.

Doping with germanium has a beneficial effect on the yield strength of silicon and will thus reduce dislocation nucleation [4]. The effect on dislocation mobility and thus also on dislocation multiplication is however limited especially at high stress levels and much smaller than e.g. the effect of dopants [18]. It can be expected, however, that doping with a low concentration of germanium has a positive effect on the crystal yield in pulling processes and also on reducing processing induced dislocation generation. Although the strengthening effect is more pronounced for higher germanium concentrations than the ones used in the present study, even for germanium concentrations below $10^{20} \mathrm{~cm}^{-3}$ it was statistically shown that wafer breakage during wafering and device processing was reduced compared to standard silicon wafers [19].

In the present paper a brief overview will be given of effects of germanium doping in the range between $10^{16} \mathrm{~cm}^{-3}$ and $10^{19} \mathrm{~cm}^{-3}$ based on previously published results of some of the authors $[5,6,7,8,9,10,14,19]$ and based on recent results on suppression of thermal donor [20], COP and FPD formation [21] as well as on effects on diode characteristics and radiation induced defects $[20,21,22]$. Whenever possible, the obtained results are compared with results obtained by other groups.

\section{Czochralski growth of germanium doped silicon crystals and diode processing}

In principle it is possible to grow germanium doped silicon (or $\mathrm{Si}_{1-x} \mathrm{Ge}_{x}$ ) crystals using the standard Czochralski pulling process with $\mathrm{x}$ up to 0.15 $[3,4]$ although for $\mathrm{x}$ values above 0.05 special attention is needed to avoid dislocation formation and large diameter ( $>4$ inch) crystal growth has not yet been demonstrated.

In the present overview, crystals are compared that were grown using the same nominal pulling conditions, the only difference being that one of the 
crystals was doped with germanium from the melt. For the study of the impact of germanium doping on diode characteristics and radiation hardness, two 4-inch diameter, n-type CZ crystals were pulled by QL electronics [23], in collaboration with the State Key Laboratory of Silicon Materials (Hangzhou, P. R. China). One of the crystals (GCZ) was doped with a germanium concentration of about $10^{19} \mathrm{~cm}^{-3}$, whereas the second crystal (CZ) was without germanium doping. Both crystals were grown under the same nominal pulling conditions and had therefore a similar resistivity and interstitial oxygen content $\mathrm{C}_{O I}$ as listed in Table 1 . The interstitial oxygen concentration in the as-grown wafers $\mathrm{C}_{O I}$ was measured with FTIR and calculated using the IOC-88 standard [24], i.e. using the $3.14 \times 10^{17} \mathrm{~cm}^{-3} / \mathrm{cm}^{-1}$ calibration constant. The apparently lower interstitial oxygen content in the germanium doped crystal is already a first indication of the fact that germanium doping enhances oxygen precipitation even during crystal pulling. Performing a high temperature treatment to dissolve the oxide clusters formed during crystal growth reveals indeed the same interstitial oxygen concentration in both types of crystals [5].

P-on-n diodes, with an active area of $0.25 \mathrm{~cm}^{2}$, were processed on polished $\langle 100\rangle$ oriented wafers prepared from both 4 inch crystals. After characterization some of the diodes were subjected to thermal treatments in $\mathrm{N}_{2} / \mathrm{H}_{2}$ or $\mathrm{N}_{2}$ annealing ambients at temperatures ranging between $250{ }^{\circ} \mathrm{C}$ and $450{ }^{\circ} \mathrm{C}$ and annealing times between $0.5 \mathrm{~h}$ and $5 \mathrm{~h}$ in order to study the formation of thermal donors in finished devices. As-grown wafers from both crystals received also the same heat treatment to study thermal donor formation. The impact of germanium doping on diode characteristics and on thermal donor formation was analyzed by means of capacitance-voltage $(\mathrm{C}-\mathrm{V})$ and current-voltage $(\mathrm{I}-\mathrm{V})$ measurements [20] and deep level transient spectroscopy (DLTS) [25]. Another set of diodes was irradiated at room temperature with $2 \mathrm{MeV}$ electrons to compare the radiation hardness of both types of diodes [22]

\section{Impact of germanium doping on crystal and wafer defects}

The Flow Pattern Defect (FPD) and Secco Etch Pit Defect (SEPD) density in $\mathrm{CZ} \mathrm{Si}$ and GCZ Si materials were investigated by etching wafers vertically inserted in Secco etchant for different times. After this the FPD and SEPD numbers were counted and the mean density was calculated. A 
typical optical micro-graph obtained after 30 min Secco etching is shown in Fig. 1 revealing the presence of FPD's and SEPD's.

FPD and SEPD densities observed in 4 inch wafers of the present study superimposed on results obtained on wafers prepared from the tail part of 5 inch as-grown CZ and GCZ Si crystals with different germanium concentrations [8] are shown in the top figure of Fig. 2. The values on the y-axes are those without germanium doping. The wafers were etched at room temperature with Secco etchant for $30 \mathrm{~min}$, removing about 30 microns of silicon. Recent published data for p-type, 5 and 6 inch, as-grown CZ and GCZ Si wafers with different germanium concentrations $[26,27]$ are included in the bottom figure of Fig. 2 showing the radial distribution of FPD's.

While for the CZ Si crystals, the FPD density in the tail and head part of the crystal are quite similar, for the GCZ Si crystals, the FPD densities in the tail part of the crystal are lower than in the head part. This might be understood by the fact that the germanium concentration increases towards the tail of the crystal due to the segregation coefficient (0.33) of germanium in silicon. Also in the 4 inch wafers studied in the present work, the FPD (and SEPD) density is lower in the germanium doped crystal than in the standard silicon crystal. At the same time, both for CZ Si and GCZ Si, the FPD density decreases with increasing crystal diameter while the SEPD density increases. This is the opposite behavior of the one reported before for silicon [28].

The COP density was measured previously on 5 inch polished wafers which revealed an increase of COP density with increasing germanium content accompanied by a decrease of COP size [10]. On the 4 inch wafers used for the diode study, a similar trend is observed. Both for the 4 and 5 inch wafers, however, the size of the COP's is so small that a large part of the sizedensity distribution falls below the detection limit of the surface inspection tool.

\section{Impact of germanium doping on diode characteristics and ther- mal donor formation}

$5 \times 5 \mathrm{~mm}^{2}$ diodes were fabricated on the 4 inch wafers, using a well established and stable process with high device yield [29]. Only small differences were observed between the diodes processed on the two types of substrates [20]. The reverse currents in the GCZ Si diodes were slightly higher than in 
their CZ Si counterparts although a somewhat higher free carrier concentration was also extracted for the GCZ Si diodes $\left(2.20 \times 10^{14} \mathrm{~cm}^{-3}\right)$ compared to the CZ Si ones $\left(2.05 \times 10^{14} \mathrm{~cm}^{-3}\right)$ (Fig. 3). This higher doping density is also in line with the lower resistivity in the starting wafers as listed in Table 1. The higher reverse current levels in the GCZ Si diodes can be associated however with the lower generation lifetimes that were measured.

Interestingly, an increase of the free carrier concentration is observed when subjecting the CZ Si and GCZ Si diodes to thermal anneals at $450{ }^{\circ} \mathrm{C}$ (Fig. 3). After a $5 \mathrm{~h}$ anneal and within the probed substrate depth that corresponds to a maximum applied reverse voltage of $100 \mathrm{~V}$, the carrier concentration increases by a factor of four and a factor of two for the CZ Si and GCZ Si substrates, respectively. This increase of the carrier concentration is due to the generation of oxygen-related thermal double donors [30] as is corroborated by the results shown in Fig. 4, in which the extracted free carrier concentration for the CZ Si and GCZ Si diodes has been plotted as a function of the thermal anneal time. The results in Figs. 3 and 4 show that the thermal donor generation rate for GCZ Si $\left(\approx 2.6 \times 10^{13} \mathrm{~cm}^{-3} \cdot \mathrm{h}^{-1}\right)$ is nearly 5 times lower than the one extracted for $\mathrm{CZ} \mathrm{Si}\left(\approx 1.26 \times 10^{14} \mathrm{~cm}^{-3} \cdot \mathrm{h}^{-1}\right)$. This last value is in good agreement with previous results obtained on CZ Si substrates with similar oxygen contents [31].

From these measurements, the TDD generation rate can also be extracted as a function of the depletion depth as is illustrated in Fig.5. It is well-known that the TDD generation rate depends strongly and in a non-linear way on the interstitial oxygen concentration $\mathrm{C}_{O I}$ as reported by Wagner and Hage [32]. The observed TDD generation rate reflects therefore also the interstitial oxygen depth profile.

The interstitial oxygen concentration $C_{O I}$ out-diffusion profile after a thermal treatment is given by [33]

$$
C_{O I}-C_{O I}^{s}=\left(C_{O I}^{0}-C_{O I}^{s}\right) \operatorname{erf}\left(\frac{x}{2 \sqrt{D_{O I} t}}\right) .
$$

$C_{O I}^{0}$ and $C_{O I}^{s}$ are the initial interstitial oxygen concentration in the bulk of the wafer and the interstitial oxygen concentration at the surface at the outdiffusion temperature $T$, respectively. $x$ is the depth below the surface, $D_{O I}$ the interstitial oxygen diffusion constant at the out-diffusion temperature $T$, while $t$ is the annealing time. The interstitial oxygen diffusivity $D_{O I}$ is given by [34] 


$$
D_{O I}=0.13 \exp \left(-\frac{2.53 e V}{k T}\right) \times \mathrm{cm}^{2} s^{-1}
$$

with $k$ the Boltzmann constant.

Taking into account that the thermal donor generation rate $r_{T D D}$ (in $\left[10^{13}\right.$ $\left.\left.\mathrm{cm}^{-3} \cdot \mathrm{h}^{-1}\right]\right)$ relates to $C_{O I}\left(\right.$ in $\left.\left[\times 10^{17} \mathrm{~cm}^{-3}\right]\right)$ as $[35]$

$$
r_{T D D} \approx A_{T D D}\left(C_{O I}\right)_{T D D}^{n}
$$

one can write (1) as

$$
\left(r_{T D D}\right)^{\frac{1}{n}}-\left(r_{T D D}^{s}\right)^{\frac{1}{n}}=\left[\left(r_{T D D}^{0}\right)^{\frac{1}{n}}-\left(r_{T D D}^{s}\right)^{\frac{1}{n}}\right] \operatorname{erf}\left(\frac{x}{2 \sqrt{D_{O I} t}}\right) .
$$

Fig.5 shows also best fits of the thermal donor generation rate in the $\mathrm{Cz}$ and GCZ Si diodes obtained by assuming that the interstitial oxygen concentration at the wafer surface is the interstitial oxygen solubility at 1100 ${ }^{\circ} \mathrm{C}$ and using as bulk interstitial oxygen concentration the average value determined with FTIR after the diode processing. It is also assumed that the $5 \mathrm{~h}$ treatment at $1100{ }^{\circ} \mathrm{C}$ during the diode processing is causing the interstitial oxygen out-diffusion profile. The solubility of interstitial oxygen in silicon is given by [34]

$$
C_{O I}^{e q}=c_{O I} \exp \left(-\frac{E_{O I}}{k T}\right) .
$$

With $c_{O I}=9 \times 10^{22}$ atoms $/ \mathrm{cm}^{3}$ and $E_{O I}=1.52 \mathrm{eV}$ this yields a solubility of $2.37 \times 10^{17}$ atoms $/ \mathrm{cm}^{3}$ at $1100{ }^{\circ} \mathrm{C}$.

Although the only fit parameters are $A_{T D D}$ and $n$, an excellent fit is obtained with $R^{2}=0.999$ and 0.995 for CZ and GCZ, respectively. The extracted $A_{T D D}$ and $n$ values are listed in Table 2 and confirm the strong suppression of TDD formation by Ge doping with a pre-factor $A_{T D D}$ that is a factor of 6 smaller for GCZ. The obtained $n$ values are in good agreement with those obtained by Newman [35]. Relation (4) is only valid for oxygen concentrations well above $4 \times 10^{17} \mathrm{~cm}^{-3}$ [33] which explains the less good fit closer to the surface especially for the GCZ diodes.

Besides the slower TDD formation in Ge doped substrates, there is a slower thermal donor formation during thermal anneals in a $\mathrm{N}_{2}$ ambient compared to a $\mathrm{N}_{2} / \mathrm{H}_{2}$ ambient [20]. This is due to a hydrogen mediated increase of interstitial oxygen diffusivity resulting in a higher TDD formation rate for anneals in a hydrogen containing atmosphere [30]. 
The thermal donors in the diode structures were also observed by DLTS as illustrated in Fig. 6 for anneals at $450{ }^{\circ} \mathrm{C}$ for 2 and $5 \mathrm{~h}$ [25]. The difference in TDD concentration observed by DLTS between CZ Si and GCZ Si, is in good agreement with the one derived from the diode characteristics and with the interstitial oxygen out-diffusion profiles.

The TDD formation has also an important impact on the diode leakage current $J_{\text {leak }}[20]$ as illustrated in Fig. 7 showing $J_{\text {leak }}$ for depletion depths of 5,10 and $15 \mu \mathrm{m}$ as function of the $2 \mathrm{~h}$ anneal temperature. The data points on the $y$-axis are for the diodes before low temperature annealing. The results show a small beneficial effect of germanium doping for annealing temperatures above $300{ }^{\circ} \mathrm{C}$ which must be related to the lower TDD generation rate in the GCZ Si substrates. It is also interesting to note that the diode leakage current initially improves by low temperature anneals and reaches a minimal value around $300{ }^{\circ} \mathrm{C}$ indicating that some unstable processing-induced defects, e.g. $B_{i^{-}} O_{i}$ related recombination centers, are removed by the low temperature anneal. The increase at higher temperatures on the other hand is a consequence of the generation of thermal donors that affect a.o. the carrier generation and recombination lifetimes.

\section{Impact of germanium doping on radiation hardness}

Diodes were irradiated at room temperature with $2 \mathrm{MeV}$ electron fluences ranging from $10^{14}$ to $10^{17} \mathrm{e} \cdot \mathrm{cm}^{-2}$ using the electron accelerator at the Takasaki Japan Atomic Energy Agency. Before and after irradiation, the current/voltage $(\mathrm{I} / \mathrm{V})$ and the capacitance/voltage $(\mathrm{C} / \mathrm{V})$ characteristics of the diodes were measured with applied voltages ranging from -20 to $1.5 \mathrm{~V}$ and 0 to $20 \mathrm{~V}$, respectively [22]. Some of the I/V results are shown in Fig. 8 as a function of the electron fluence for different forward and reverse biases. The ratio of the leakage current after and before irradiation, scales with the electron fluence with the same slope for the CZ and GCZ Si diodes while the ratio for the $\mathrm{CZ}$ Si diodes is about a factor of 3 higher than for the GCZ $\mathrm{Si}$ diodes. Extrapolation to lower fluences suggests that a ratio of 1, i.e. no effect on the leakage current, is obtained for fluences below a few times $10^{12}$ $\mathrm{e} \cdot \mathrm{cm}^{-2}$. 
5.1. Diode forward characteristics and minority carrier recombination lifetime

The forward current at $0.25 \mathrm{~V}$ bias is dominated by trap-assisted recombination in the depletion region and therefore increases with increasing electron fluence. For forward voltages larger than $\sim 0.5 \mathrm{~V}$, the forward current in both types of diodes is decreasing with increasing $2 \mathrm{MeV}$ electron fluence. This is due to the increasing resistivity of the substrate related to dopant deactivation by the irradiation induced point defects.

Taking into account that the diode characteristics are thus also influenced by the serial resistance $R_{s}$ of the substrate, one can write the forward diode current $I$ as [36]

$$
I=\frac{n V_{t h}}{R_{s}} W\left(\frac{I_{0} R_{s}}{n V_{t h}} \exp \left[\frac{\left(V+I_{0} R_{s}\right)}{n V_{t h}}\right]\right)-I_{0}
$$

with $V_{t h}=\frac{k T}{q}$ the thermal voltage which at room temperature is about 25 $\mathrm{mV}, n$ the ideality factor of the diode, $W(x)$ the Lambert $\mathrm{W}$ function, $I_{0}$ the reverse saturation current and $V$ the applied voltage.

From the excellent best fit of (6) to the forward diode characteristics measured between $0.02 \mathrm{~V}$ and $0.9 \mathrm{~V}$ in steps of $0.02 \mathrm{~V}$ (Fig. 9), $I_{0}, R_{s}$ and $n$ can be extracted as listed in Table 3 .

$J_{0}$ is composed of a diffusion $\left(J_{d}\right)$ and a recombination $\left(J_{r}\right)$ part with [37]

$$
\frac{J_{r}}{J_{d}} \approx \frac{n-1}{1-0.5 n} .
$$

Before irradiation, $n$ is about 1.06 and 1.05 for CZ and GCZ, respectively, in excellent agreement with previous results [37]. This corresponds with $I_{r} / I_{d} \approx 0.13$ and 0.11 , respectively, and illustrates that the recombination current in as processed diodes is much smaller than the diffusion current. Irradiation with $10^{16} \mathrm{~cm}^{-2} 2 \mathrm{MeV}$ electrons leads to an increase of $n$ to about 1.29 and 1.30 , respectively, corresponding with $I_{r} / I_{d} \approx 0.82$ and 0.86 showing that the irradiation induced deep level related recombination component has become fully dominant.

The current density $J_{0}=\frac{I_{0}}{A}$, with $A=0.25 \mathrm{~cm}^{2}$ the diode area, is in first approximation given by [37]

$$
J_{0} \approx q \sqrt{\frac{D_{n, p}}{\tau_{r}}} \frac{n_{i}^{2}}{N_{d}} .
$$


$D_{n} \approx 36 \mathrm{~cm}^{2} \mathrm{~s}^{-1}$ is the electron diffusion coefficient and $D_{p} \approx 12 \mathrm{~cm}^{2} \mathrm{~s}^{-1}$ is the one for holes to be used for the n-type substrates of the present study. $\tau_{r}$ is the minority carrier recombination lifetime. $\mathrm{n}_{i} \approx 1.45 \times 10^{10} \mathrm{~cm}^{-3}$ at $300 \mathrm{~K}$, is the intrinsic carrier concentration and $N_{d}$ the dopant density. The dopant density can be determined from capacitance-voltage measurements yielding the results listed in Table 4 , revealing a slight increase of the carrier density by the electron irradiation for $2 \mathrm{MeV}$ electron fluences below $10^{16} \mathrm{~cm}^{-2}$. Using (8), the $I_{0}$ value extracted from the best fit of the forward diode characteristics thus allows also to extract the minority carrier recombination lifetime as listed in Table 2 and shown in Fig.10.

The impact of the $2 \mathrm{MeV}$ electron irradiation on the minority carrier recombination lifetime $\tau_{r}$ can be written as

$$
\frac{1}{\tau_{r}}=\frac{1}{\tau_{r}^{0}}+K_{r} \Phi^{n_{r}}
$$

with $n_{r}$ and damage coefficient $K_{r}$ fit parameters and $\tau_{r}^{0}$ the minority carrier recombination lifetime in the diode substrates before irradiation. The results of the best fit are listed in Table 2. The $R^{2}$ values are 0.9916 and 0.9996 for the $\mathrm{CZ}$ and GCZ diodes, respectively. Due to the strong dopant deactivation, the data for the $10^{17} \mathrm{~cm}^{-2} 2 \mathrm{MeV}$ electron fluence were not included in the fit.

\subsection{Diode reverse characteristics and carrier generation lifetime}

The impact of the $2 \mathrm{MeV}$ electron irradiation on the carrier generation lifetime $\tau_{g}$ can be calculated from the dependence of the reverse generation current density $J_{r}$ and the diffusion current density $J_{d}$ on the reverse bias. In first order approximation one can indeed write [38]

$$
J_{r}=J_{d}+\frac{q n_{i} W_{d e p}}{\tau_{g}},
$$

with the depletion width $W_{d e p}$ given by

$$
W_{d e p}=\sqrt{\frac{2 \epsilon_{0} \epsilon_{S i}\left(V_{r}+V_{b i}\right)}{q N_{d}} .}
$$

$V_{b i}$ is the built-in potential, $V_{r}$ the reverse bias, $\epsilon_{0}=8.85 \times 10^{-14} \mathrm{Fcm}^{-1}$ the permittivity of vacuum and $\epsilon_{S i}=11.9$ the dielectric constant of silicon.

The built-in potential is given by 


$$
V_{b i}=\frac{k T}{q} \ln \frac{N_{A} N_{D}}{p_{0} n_{0}} \approx 0.76 \mathrm{~V},
$$

with $p_{0} n_{0} \approx n_{i}^{2}$. An excellent fit it is obtained when fitting the reverse current calculated with (10) to the measured values for a reverse bias varying from 0.2 to $20.2 \mathrm{~V}$.

In Fig. 10, the degradation of the recombination and generation lifetimes $\tau_{r}$ and $\tau_{g}$, respectively, is illustrated as a function of the $2 \mathrm{MeV}$ electron fluence. The figure reveals again that there is a limited effect of the $10^{19}$ $\mathrm{cm}^{-3}$ germanium doping, in particular on the minority carrier recombination lifetime.

The electrical characteristics are connected with the trap parameters of the deep level that dominates the generation and recombination lifetimes by $[39]$

$$
\begin{gathered}
\frac{\tau_{g}}{\tau_{r}} \approx \cosh \left(\frac{E_{T}-E_{F}}{k T}\right) . \\
\tau_{r} \approx \frac{1}{N_{T} \sigma v_{t h}} .
\end{gathered}
$$

$E_{T}$ and $E_{F}$ are the trap level and the Fermi level, respectively. $N_{T}$ is the trap density as can be determined e.g. by DLTS while $v_{t h} \approx 10^{7} \mathrm{~cm} \times \mathrm{s}^{-1}$ is the thermal carrier velocity. The extracted generation-recombination center position in the bandgap is listed in Table 4 for both types of diodes as a function of the $2 \mathrm{MeV}$ electron fluence. The results point to the A-center $\left(\mathrm{E}_{C}-0.18 \mathrm{eV}\right)$ or/and the di-vacancy $\left(\mathrm{E}_{C}-0.23 \mathrm{eV}\right)$ or/and a carbon-oxygen related level $\left(\mathrm{E}_{V}+0.36\right)$ as dominant generation-recombination centers in the irradiated diodes in agreement with DLTS results on similar samples [25]. For the $10^{14} \mathrm{~cm}^{-2} 2 \mathrm{MeV}$ electron fluence, the A-center concentration observed with DLTS is about 6 and $7 \times 10^{12} \mathrm{~cm}^{-3}$ for the CZ and GCZ diodes, respectively [25]. This would correspond with a effective capture cross-sections of about $8.5 \times 10^{-14} \mathrm{~cm}^{2}$ and $4.5 \times 10^{-13} \mathrm{~cm}^{2}$ for CZ and GCZ, respectively, in fair agreement with the $10^{-14} \mathrm{~cm}^{2}$ value obtained with DLTS for the A-center.

Similar to the case for $\tau_{r}$, the dependence of $\tau_{g}$ on the $2 \mathrm{MeV}$ electron fluence $\Phi$ (in electrons $\times \mathrm{cm}^{-2}$ ) can empirically be written as

$$
\frac{1}{\tau_{g}}=\frac{1}{\tau_{g}^{0}}+K_{g} \Phi^{n_{g}}
$$


with $n_{g}$ and damage coefficient $K_{g}$ fit parameters and $\tau_{g}^{0}$ the generation lifetime (in $s$ ) in the diode substrates before irradiation. Also in this case a good logarithmic fit is obtained using (10) with in both cases a $R^{2}$ value of 0.9991 . Due to the strong dopant deactivation, the data for the $10^{17} \mathrm{~cm}^{-2} 2 \mathrm{MeV}$ electron fluence were not included in the fit. The extracted fit parameters are listed in Table 2.

With respect to diode characteristics, there is thus only a small effect of $10^{19} \mathrm{~cm}^{-3}$ germanium doping on electron irradiation hardness. Higher concentrations of germanium $(\mathrm{x}>0.15)$ lead however to significant radiation hardening of devices as was observed in strained $\mathrm{Si}_{1-x} \mathrm{Ge}_{x}$ epitaxial devices for electron and neutron irradiation [40, 41] and for proton irradiation [42].

As-grown samples (after Schottky diode fabrication by metal evaporation) and diodes irradiated at room temperature were also characterized with DLTS. The deep level concentrations are always somewhat higher in the germanium doped substrates in agreement with the results of Londos $[11,12,13]$.

The results above illustrate that $\mathrm{p}-\mathrm{n}$ diodes are very useful to study carrier lifetime and the electronic properties of lattice defects in semiconductor materials. A recent, more extended review on this topic, including also the study of irradiation induced defects and thermal donor formation, was published elsewhere [43].

\section{Conclusions}

Doping of silicon with germanium concentrations in the range between $10^{16}$ and $10^{19} \mathrm{~cm}^{-3}$ is beneficial for the crystal and wafer quality as it improves the mechanical strength leading to lower wafer losses due to breaking, during wafer cutting and thermal processing. Furthermore, germanium doping clearly suppresses thermal donor formation while at the same time it can strongly enhance oxygen precipitation and thus increase the internal gettering capacity of low oxygen content wafers which are both relevant advantages for device processing.

In the present study, however, only limited effects of germanium doping on diode characteristics ( $\mathrm{I} / \mathrm{V}$ and $\mathrm{C} / \mathrm{V}$ ) before and after electron irradiation are observed, confirming that low concentration doping with germanium has no significant effect on device characteristics and therefore does not have to be taken into account in device design. A further advantage is that also the 
crystal pulling process itself does not need any modification for germanium concentrations below $10^{20} \mathrm{~cm}^{-3}$.

Further work is planned on GCZ Si substrates with higher germanium doping levels in the range between $10^{20}$ and $10^{21} \mathrm{~cm}^{-3}$, in order to explore the described effects also for higher germanium concentrations that still can be added to the silicon melt without strongly affecting the crystal growth process and stability.

\section{Acknowledgments}

J. Chen and J. Vanhellemont acknowledge the National Natural Science Foundation of China (NSFC, Grant No. 50832006 and 60906001) and the Research Foundation-Flanders (FWO) for financial support. H. Vrielinck acknowledges a Postdoctoral Fellowship with FWO. Part of this work was supported by the Inter-University Laboratory for the Joint Use of JAERI Facilities. 
[1] V. V. Voronkov and R. Falster, J. Cryst. Growth 194 (1998) 76.

[2] J. Vanhellemont, P. Śpiewak, K. Sueoka and I. Romandic, Phys. Stat. Sol. C 6 (2009) 1906.

[3] N.V. Abrosimov, S.N. Rossolenko, W. Thieme, A. Gerhardt and W. Schröder, J. Cryst. Growth 174 (1997) 182.

[4] I. Yonenaga, J. Cryst. Growth 275 (2005) 91.

[5] H. Li, D. Yang, X. Ma, X. Yu and D. Que, J. Appl. Phys. 96 (2004) 4161.

[6] J. Chen, D. Yang, X. Ma, R. Fan and D. Que, J. Appl. Phys. 102 (2007) 066102 .

[7] C. Cui, D. Yang, X. Ma, M. Li and D. Que, Mat. Sci. Semicond. Proc. 9 (2006) 110.

[8] D. Yang, X. Yu, X. Ma, J. Xu, L. Li and D. Que, J. Cryst. Growth 243 (2002) 371.

[9] D. Yang, J. Chen, H. Li, X. Ma, D. Tian, L. Li and D. Que, J. Cryst. Growth 292 (2006) 266.

[10] J. Chen, D. Yang, H. Li, X. Ma, D. Tian, L. Li and D. Que, J. Cryst. Growth 306 (2007) 262.

[11] C.A. Londos, A. Andrianakis, V. Emtsev and H. Ohyama, J. Appl. Phys. 105 (2009) 123508.

[12] C.A. Londos, A. Andrianakis, V.V. Emtsev and H. Ohyama, Semicond. Sci. Technol. 24 (2009) 075002.

[13] C.A. Londos, A. Andrianakis, V.V. Emtsev, G.A. Oganesyan and H. Ohyama, Physica B 404 (2009) 4693.

[14] J. Chen, T. Wu, X. Ma, L. Wang and D. Yang, J. Appl. Phys. 103 (2008) 123519 .

[15] A. Chroneos, R.W. Grimes and H. Bracht, J. Appl. Phys. 105 (2009) 016102. 
[16] J. Vanhellemont, M. Suezawa and I. Yonenaga, J. Appl. Phys. 108 (2010) 016105.

[17] J. Vanhellemont, X. Zhang, W. Xu, J. Chen, X. Ma and D. Yang, accepted for publication in J. Appl. Phys.

[18] I. Yonenaga, T. Taishi, X. Huang and K. Hoshikawa, J. Appl. Phys. 93 (2003) 265.

[19] J. Chen, D. Yang, X. Ma, Z. Zeng, D. Tian, L. Li, D. Que and L. Gong, J. Appl. Phys. 103 (2008) 123521.

[20] J.M. Rafí, J. Vanhellemont, E. Simoen, J. Chen, M. Zabala, F. Campabadal, Physica B 404 (2009) 4723.

[21] J. Vanhellemont, J. Chen, W. Xu, D. Yang, J.M. Rafi, H. Ohyama and E. Simoen, ECS Transactions 27 (2010) 1041.

[22] H. Ohyama, J.M. Rafí, K. Takakura, E. Simoen, J. Chen and J. Vanhellemont, Physica B 404 (2009) 4671.

[23] QL Electronics, 20 Gangdong Road, Ningbo Free Trade Zone, Ningbo 315800, Peoples Republic of China.

[24] A. Baghdadi, W. M. Bullis, M. C. Croarkin, Y.-Z. Li, R. I. Scace, R. W. Series, P. Stallhofer and M. Watanabe, J. Electrochem. Soc. 136 (1989) 2015.

[25] J. Chen, J. Vanhellemont, E. Simoen, J. Lauwaert, H. Vrielinck, J.M. Rafí, H. Ohyama, J. Weber and D. Yang, phys. stat. sol. c, in press.

[26] M. Arivanandhan, R. Gotoh, K. Fujiwara and S. Uda, J. Appl. Phys. 106 (2009) 013721.

[27] J. Chen, PhD thesis, Zhejiang University (2008) (in Chinese).

[28] T. Abe, Material Science and Engineering B73 (2000) 16.

[29] C. Martínez, J.M. Rafí, M. Lozano, F. Campabadal, J. Santander, L. Fonseca, M. Ullán and A. Moreno, IEEE Trans. Nucl. Sci. 49 (2002) 1377. 
[30] E. Simoen, Y.L. Huang, Y. Ma, J. Lauwaert, P. Clauws, J.M. Rafí, A. Ulyashin, C. Claeys, J. Electrochem. Soc. 156 (2009) H434.

[31] J.M. Rafí, E. Simoen, C. Claeys, Y.L. Huang, A.G. Ulyashin, R. Job, J. Versluys, P. Clauws, M. Lozano and F. Campabadal, J. Electrochem. Soc. 152 (2005) G16.

[32] P. Wagner and J. Hage, Appl. Phys. A 49 (1989) 123.

[33] Y. Sugita, H. Kawata, S. Nakamichi, T. Okabe, T. Watanabe, S. Yoshikawa, Y. Itoh and T. Nozaki, Jap. J. Appl. Phys. 24 (1985) 1302.

[34] A. Borghesi, B. Pivac, A. Sassella and A. Stella, J. Appl. Phys. 77 (1995) 4169.

[35] R.C. Newman, J. Phys.: Condens. Matter 12 (2000) R335.

[36] A. Ortiz-Conde and F. J. García Sánchez, Solid-State Electronics 49 (2005) 465.

[37] J. Vanhellemont, E. Simoen and C. Claeys, Appl. Phys. Lett. 66 (1995) 2894.

[38] J. Vanhellemont, E. Simoen, A. Kaniava, M. Libezny and C. Claeys, J. Appl. Phys. 77 (1995) 5669.

[39] E. Simoen, J. Vanhellemont and C. Claeys, Appl. Phys. Lett. 69 (1996) 2858.

[40] H. Ohyama, J. Vanhellemont, Y. Takami, K. Hayama, H. Sunaga, J. Poortmans, M. Caymax and P. Clauws, IEEE Trans. Nucl. Sci. 41 (1994) 2437.

[41] H. Ohyama, J. Vanhellemont, Y. Takami, K. Hayama, H. Sunaga, J. Poortmans and M. Caymax, IEEE Trans. Nucl. Sci. 42 (1995) 1550.

[42] H. Ohyama, K. Hayama, J. Vanhellemont, J. Poortmans, M. Caymax, Y. Takami, H. Sunaga, I. Nashiyama and Y. Uwatoko, Appl. Phys. Lett. 69 (1996) 2429.

[43] E. Simoen, C. Claeys and J. Vanhellemont, Defect and Diffusion Forum Vols. 261-262 (2007) 1. 
Table 1: Main specifications of the CZ and GCZ Si substrates used in the present study. For both types of substrates, the oxygen concentration was measured on 3 samples from the same wafer.

Substrate

Type

Orientation

Thickness $[\mu \mathrm{m}]$

Resistivity $[\Omega \cdot \mathrm{cm}]$

Dopant concentration $\left[\times 10^{14} \mathrm{~cm}^{-3}\right]$

$C_{O I}^{0}\left[\times 10^{17} \mathrm{~cm}^{-3}\right]$

Ge concentration $\left[\mathrm{cm}^{-3}\right]$

\section{CZ Si $\quad$ GCZ Si}

$\mathrm{n} n$

$<100>\quad<100>$

$525 \pm 15 \quad 525 \pm 15$

$23.7 \pm 2.4 \quad 19.4 \pm 1.0$

$1.84 \pm 0.21 \quad 2.25 \pm 0.12$

$9.51 \pm 0.24 \quad 8.090 \pm 0.051$

$0 \sim 10^{19}$ 
Table 2: Material parameters extracted from the diode characteristics and substrates. For both types of diodes, the oxygen concentration was measured on 3 samples after removal of the diode structures.

$\begin{array}{lcc}\text { Substrate } & \text { CZ Si } & \text { GCZ Si } \\ C_{O I}^{d}\left[\times 10^{17} \mathrm{~cm}^{-3}\right] & 9.547 \pm 0.029 & 8.050 \pm 0.051 \\ A_{T D D}\left[\times 10^{-4}\right] & 21.5 \pm 2.1 & 3.53 \pm 0.70 \\ n_{T D D} & 4.296 \pm 0.049 & 4.80 \pm 0.11 \\ \tau_{g}^{0}[m s] & 4.240 \pm 0.043 & 6.959 \pm 0.094 \\ n_{g} & 0.840 \pm 0.026 & 0.805 \pm 0.024 \\ \log _{10}\left(K_{g}\right) & -7.98 \pm 0.39 & -7.65 \pm 0.36 \\ \tau_{r}^{0}[m s] & 2.14 \pm 0.24 & 5.88 \pm 0.67 \\ n_{r} & 1.83 \pm 0.17 & 1.955 \pm 0.040 \\ \log _{10}\left(K_{r}\right) & -19.8 \pm 2.5 & -22.16 \pm 0.60\end{array}$


Table 3: CZ and GCZ Si diode characteristics before and after $2 \mathrm{MeV}$ electron irradiation extracted from fitting (6) between 0.02 and $0.9 \mathrm{~V}$.

$\begin{array}{llllll}\text { Diode } & \begin{array}{l}2 \mathrm{MeV} \text { e } \\ \text { fluence }\end{array} & \mathrm{I} & \mathrm{R}_{s} & \mathrm{R}^{2} \\ & {\left[\mathrm{~cm}^{-2}\right]} & {\left[10^{-9} \mathrm{~A}\right]} & & {[\Omega]} & \\ \mathrm{CZ} \mathrm{Si} & 0 & (3.11 \pm 0.18) \times 10^{-3} & 1.0622 \pm 0.0051 & 8.74 \pm 0.42 & 0.99969 \\ & 10^{14} & (1.091 \pm 0.043) \times 10^{-1} & 1.1221 \pm 0.0048 & 14.83 \pm 0.47 & 0.99980 \\ & 10^{15} & 1.22 \pm 0.10 & 1.276 \pm 0.014 & 19.0 \pm 1.3 & 0.99884 \\ & 10^{16} & 7.17 \pm 0.44 & 1.287 \pm 0.012 & 25.5 \pm 1.2 & 0.99931 \\ & 10^{17} & 204.1 \pm 3.1 & 1.1475 \pm 0.0061 & 1814 \pm 24 & 0.99995 \\ \text { GCZ Si } & 0 & (1.658 \pm 0.094) \times 10^{-3} & 1.0464 \pm 0.0048 & 7.66 \pm 0.38 & 0.99970 \\ & 10^{14} & (4.93 \pm 0.29) \times 10^{-2} & 1.1126 \pm 0.0065 & 10.30 \pm 0.50 & 0.99959 \\ & 10^{15} & (4.85 \pm 0.27) \times 10^{-1} & 1.2069 \pm 0.0076 & 7.07 \pm 0.33 & 0.99955 \\ & 10^{16} & 4.06 \pm 0.15 & 1.3014 \pm 0.0062 & 7.63 \pm 0.23 & 0.99977 \\ & 10^{17} & 99.4 \pm 1.5 & 1.1172 \pm 0.0052 & 1804 \pm 22 & 0.99995\end{array}$


Table 4: Carrier density, extracted from the $\mathrm{C}-\mathrm{V}$ diode characteristics and the position $E_{T}-E_{F}$ in the bandgap of the generation-recombination center calculated from (13), both as function of the $2 \mathrm{MeV}$ electron fluence.

\begin{tabular}{|c|c|c|c|c|}
\hline $\begin{array}{l}\text { Fluence } \\
{[\times 2 \mathrm{MeVecm}}\end{array}$ & $\begin{array}{l}\text { Carrier density } \\
{\left[\times 10^{14} \mathrm{~cm}^{-3}\right]}\end{array}$ & & $\begin{array}{l}E_{T}-E_{F} \\
{[\times e V]}\end{array}$ & \\
\hline & $\mathrm{CZ} \mathrm{Si}$ & GCZ Si & $\mathrm{CZ} \mathrm{Si}$ & GCZ Si \\
\hline 0 & 2.03 & 2.29 & 0.034 & 0.015 \\
\hline $10^{14}$ & 2.06 & 2.32 & 0.14 & 0.11 \\
\hline $10^{15}$ & 2.11 & 2.42 & 0.21 & 0.18 \\
\hline $10^{16}$ & 2.12 & 2.54 & 0.26 & 0.25 \\
\hline
\end{tabular}




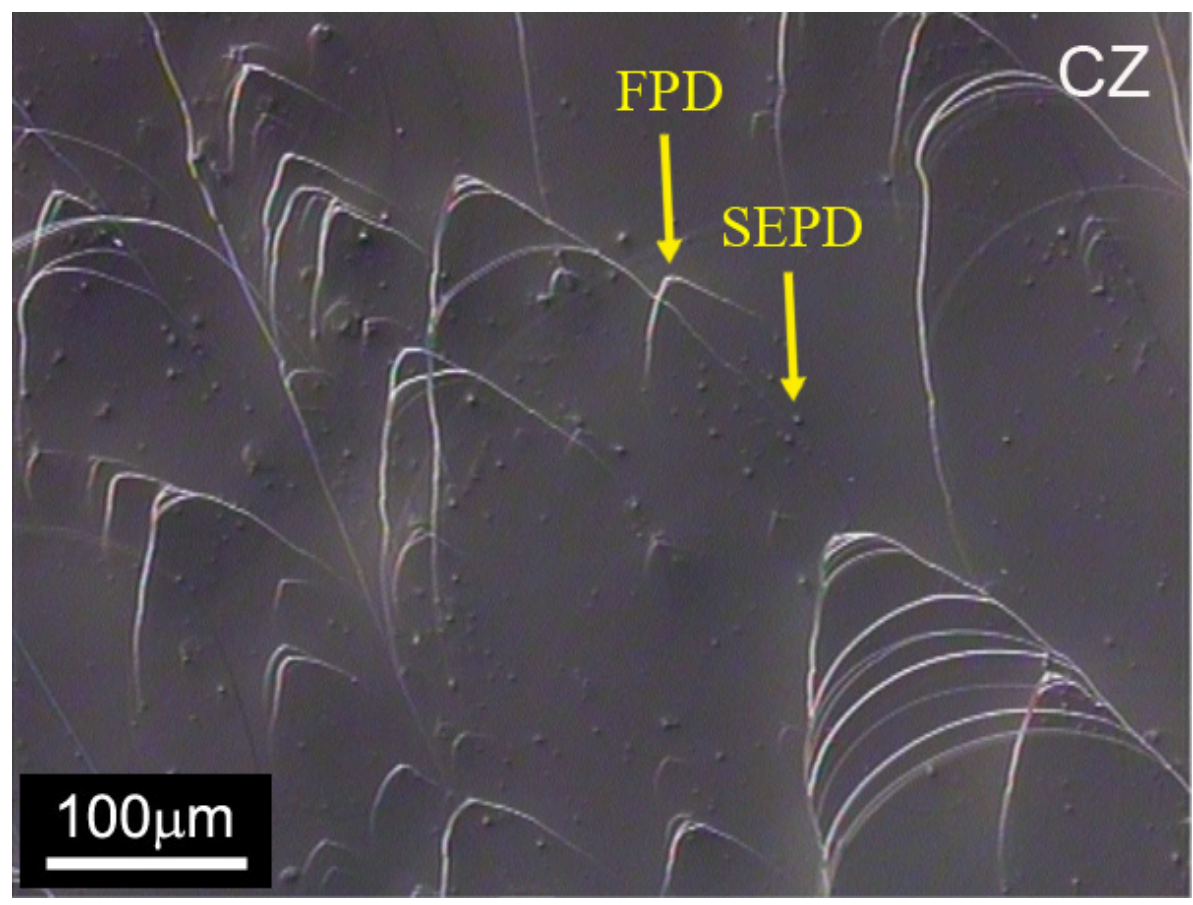

Figure 1: Optical micro-graph showing FPD's and SEPD's after 30-min Secco-etching of 4 inch $\mathrm{CZ}$ silicon wafer. 

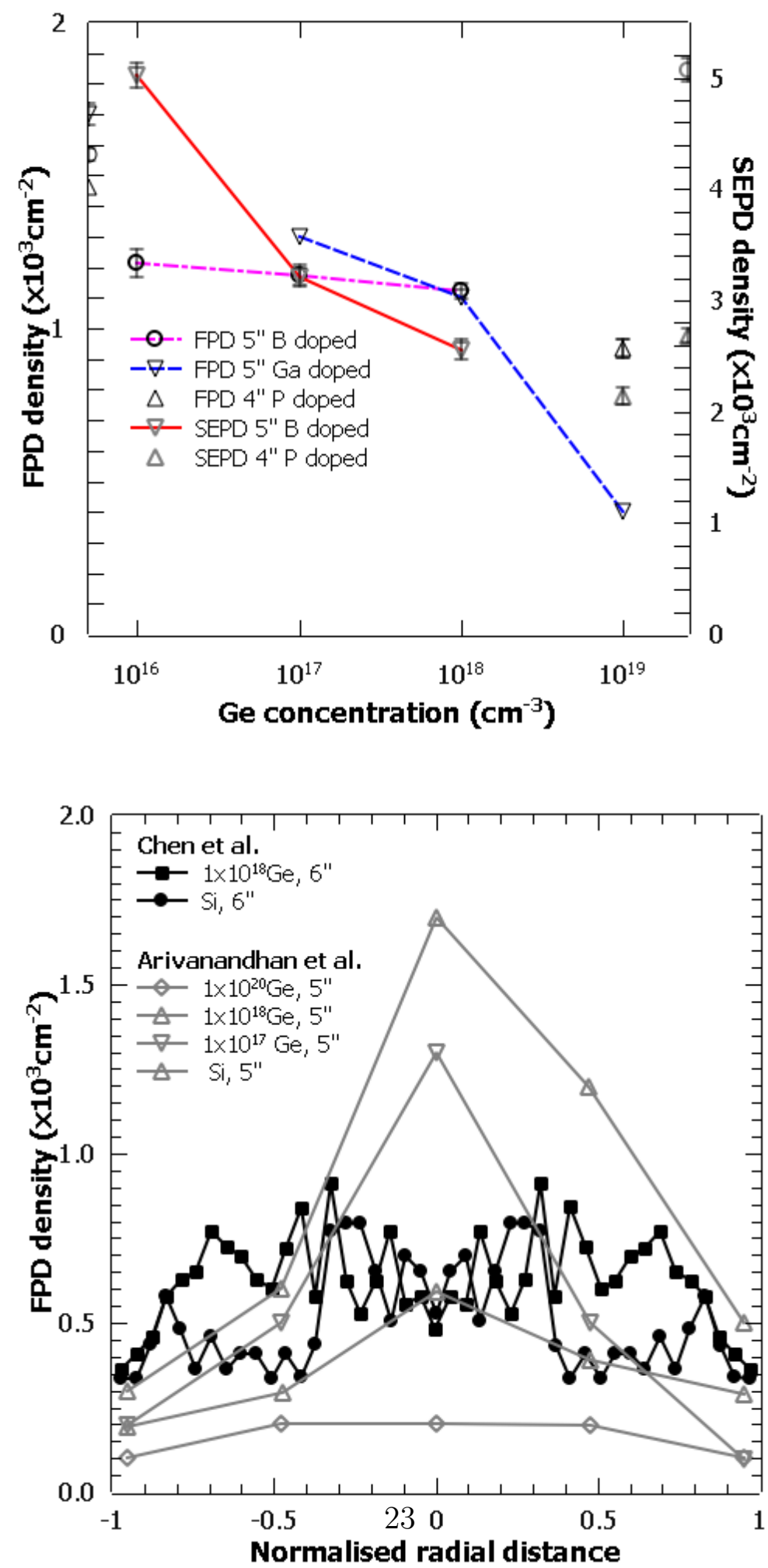

Figure 2: Top: FPD and SEPD densities observed in 4 inch wafers of the present study superimposed on results obtained on wafers prepared from the tail part of 5 inch as-grown CZ and GCZ Si crystals with different germanium concentrations [8]. Recent data for Ga doped 5 inch wafers are also included [26]. The values on the y-axes are those without germanium doping. Bottom: Radial variation of FPD density as a function of germanium doping for 5 and 6 inch p-type crystals $[26,27]$. 


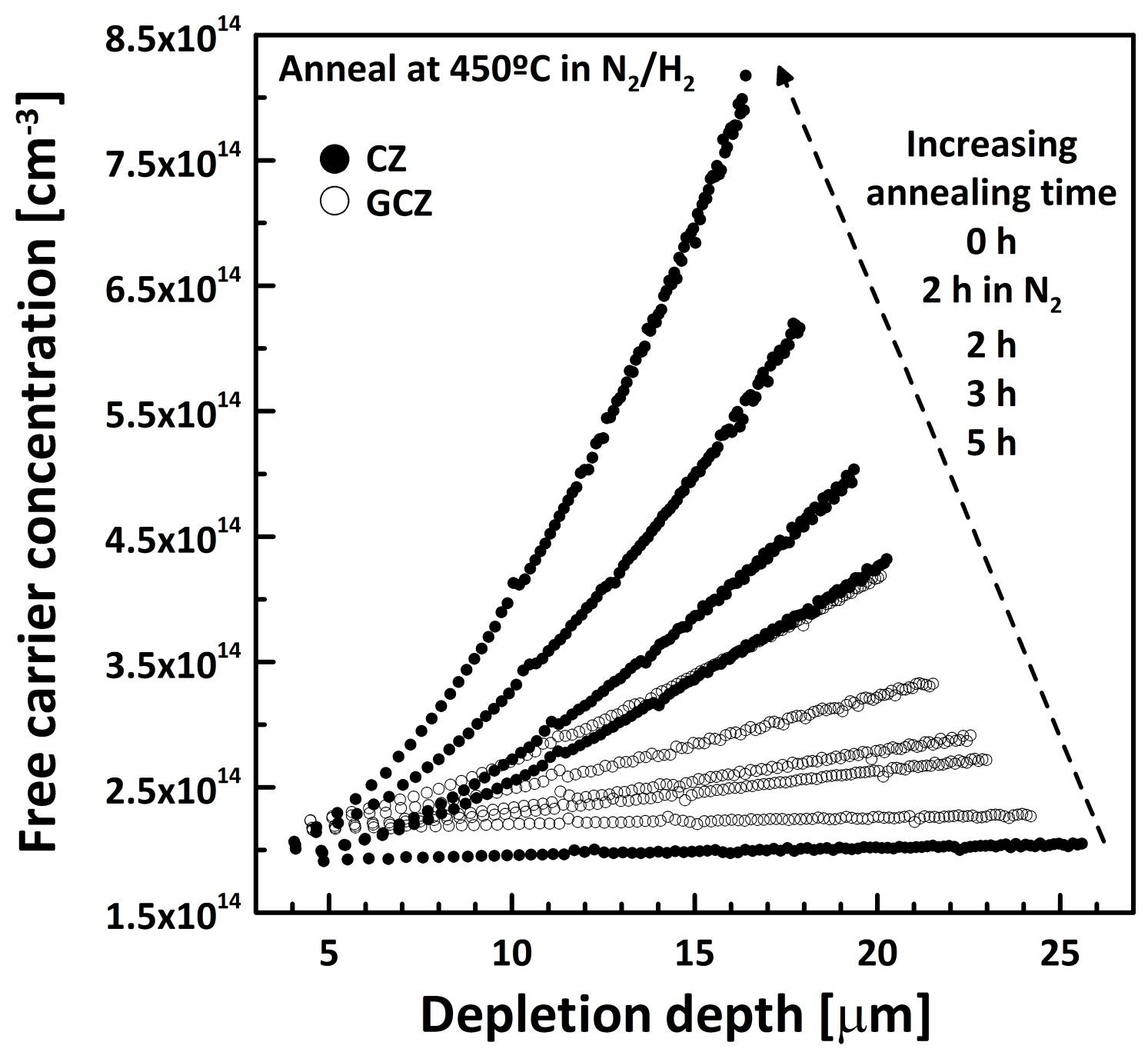

Figure 3: Free carrier concentration versus depletion width for CZ Si and GCZ Si diodes for different thermal annealing times [20]. The higher initial carrier density in the GCZ Si substrates is also illustrated. 


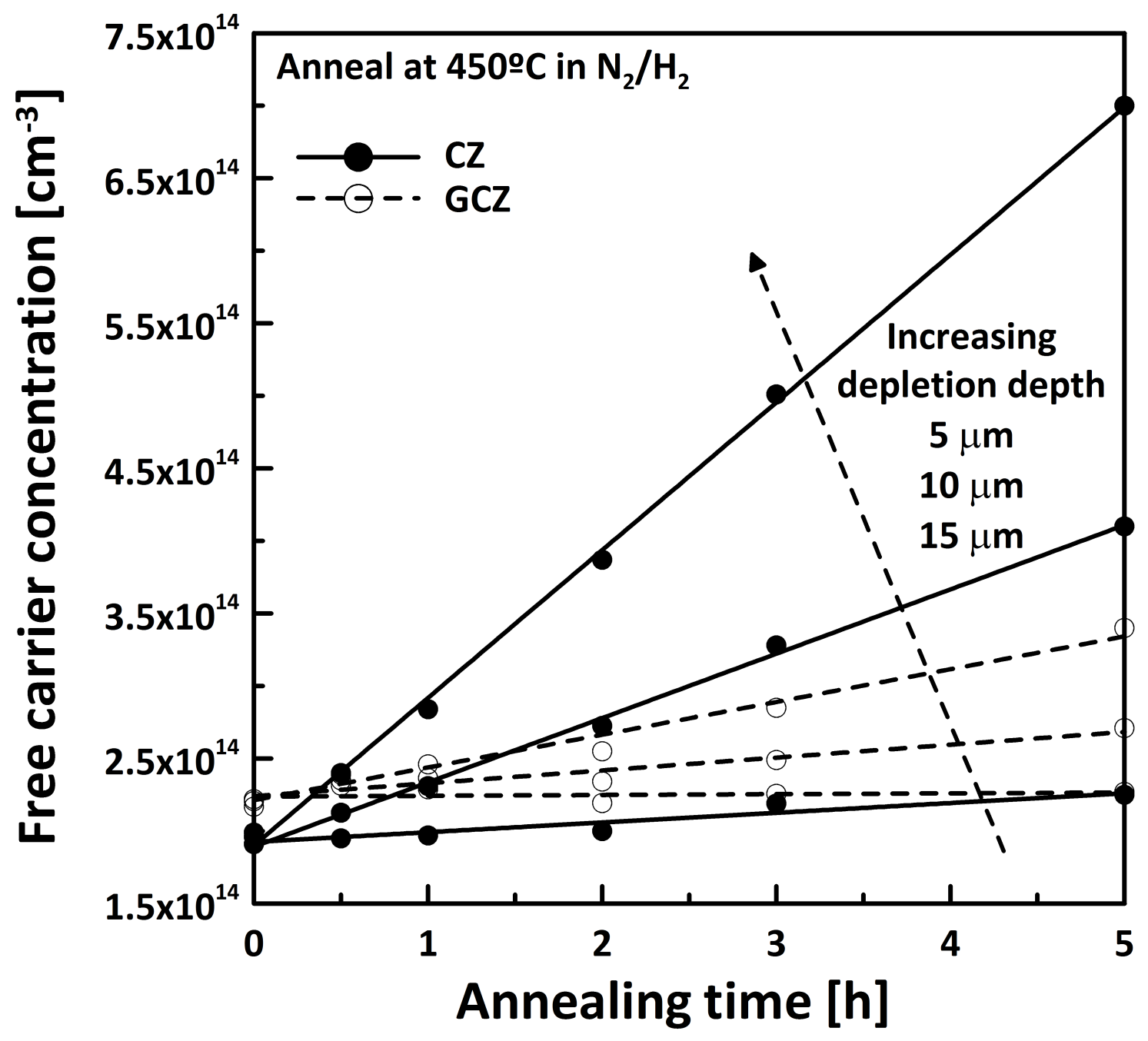

Figure 4: Extracted free carrier concentration for CZ Si and GCZ Si p-on-n diodes as a function of thermal annealing time $450{ }^{\circ} \mathrm{C}$. The carrier concentrations correspond to the values for depletion width's of 5,10 and $15 \mu \mathrm{m}$ [20]. 


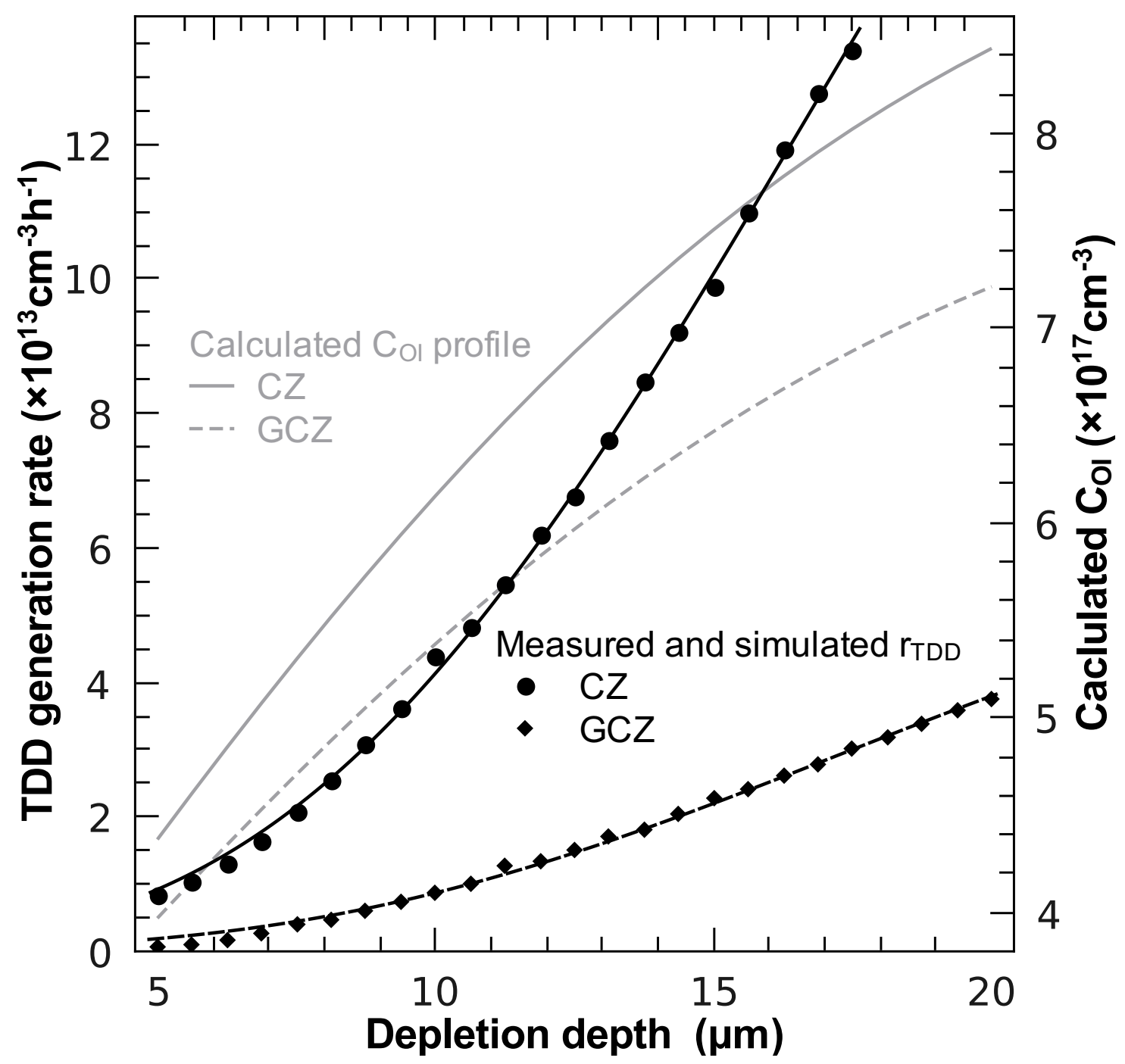

Figure 5: Extracted TDD generation rates and best fits using (4), as a function of depletion depth for CZ Si and GCZ p-on-n diodes subjected to different thermal annealing times at $450{ }^{\circ} \mathrm{C}$. The corresponding interstitial oxygen concentration depth profiles calculated with (1) are also shown. 


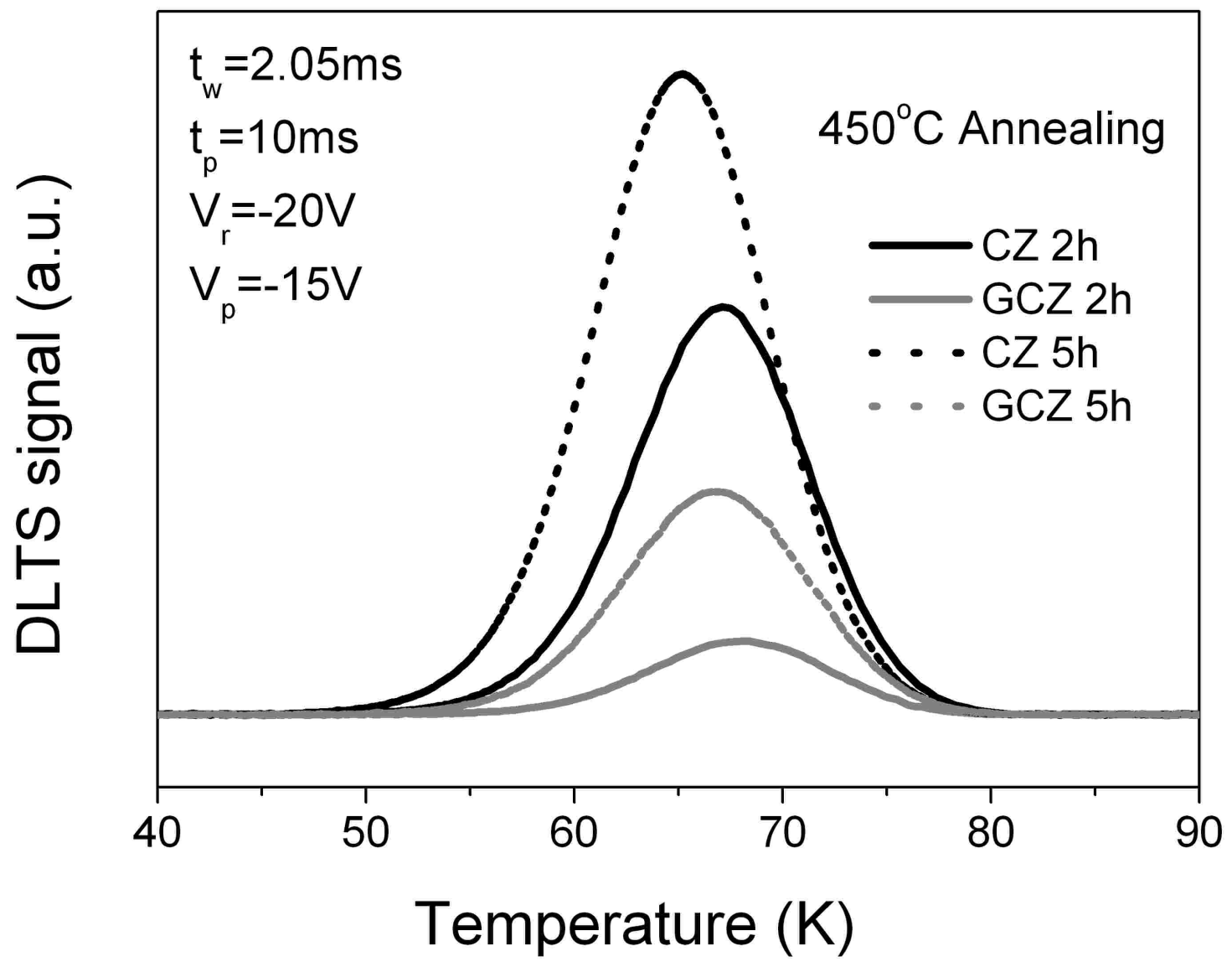

Figure 6: DLTS spectra of diode structures annealed for 2 and $5 \mathrm{~h}$ at $450{ }^{\circ} \mathrm{C}$ [25]. 


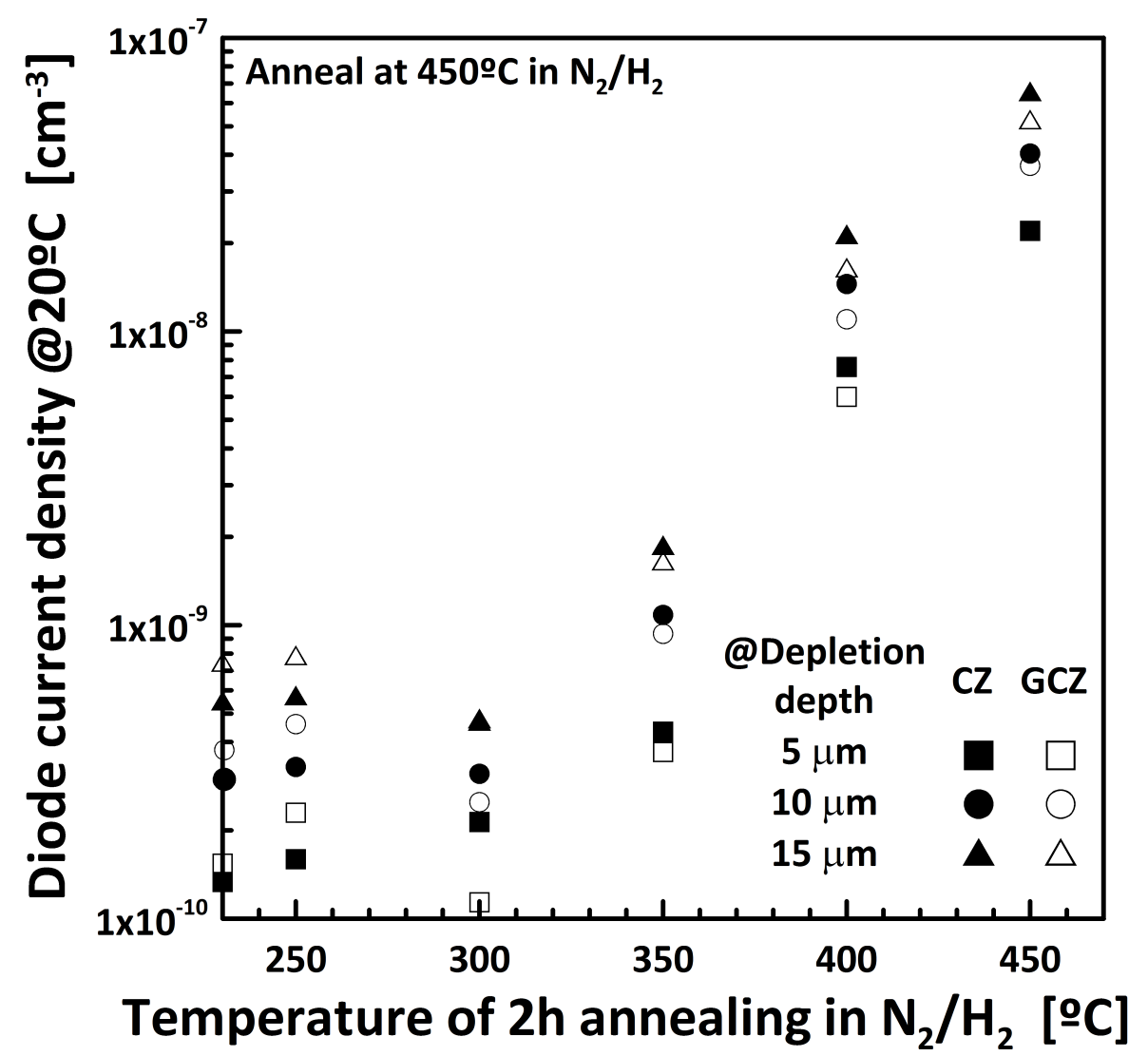

Figure 7: Diode leakage current for depletion depths of 5, 10 and $15 \mu \mathrm{m}$ as function of the $2 \mathrm{~h}$ thermal anneal temperature. The data points on the y-axis are for the diodes before low temperature anneal. 

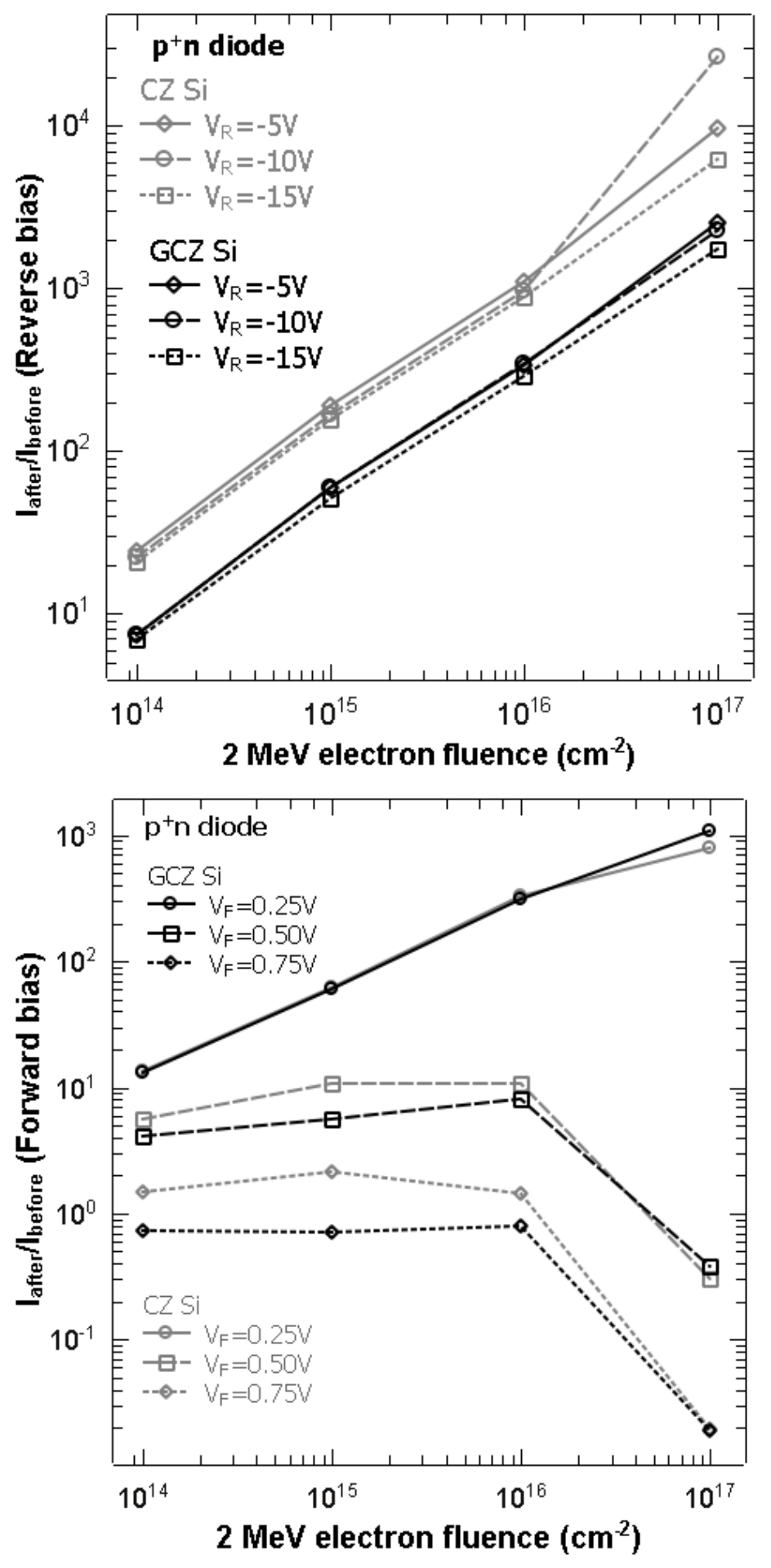

29

Figure 8: Normalized current for reverse (top) and forward (bottom) bias of CZ Si and GCZ Si diodes after $2 \mathrm{MeV}$ electron irradiation [22]. 

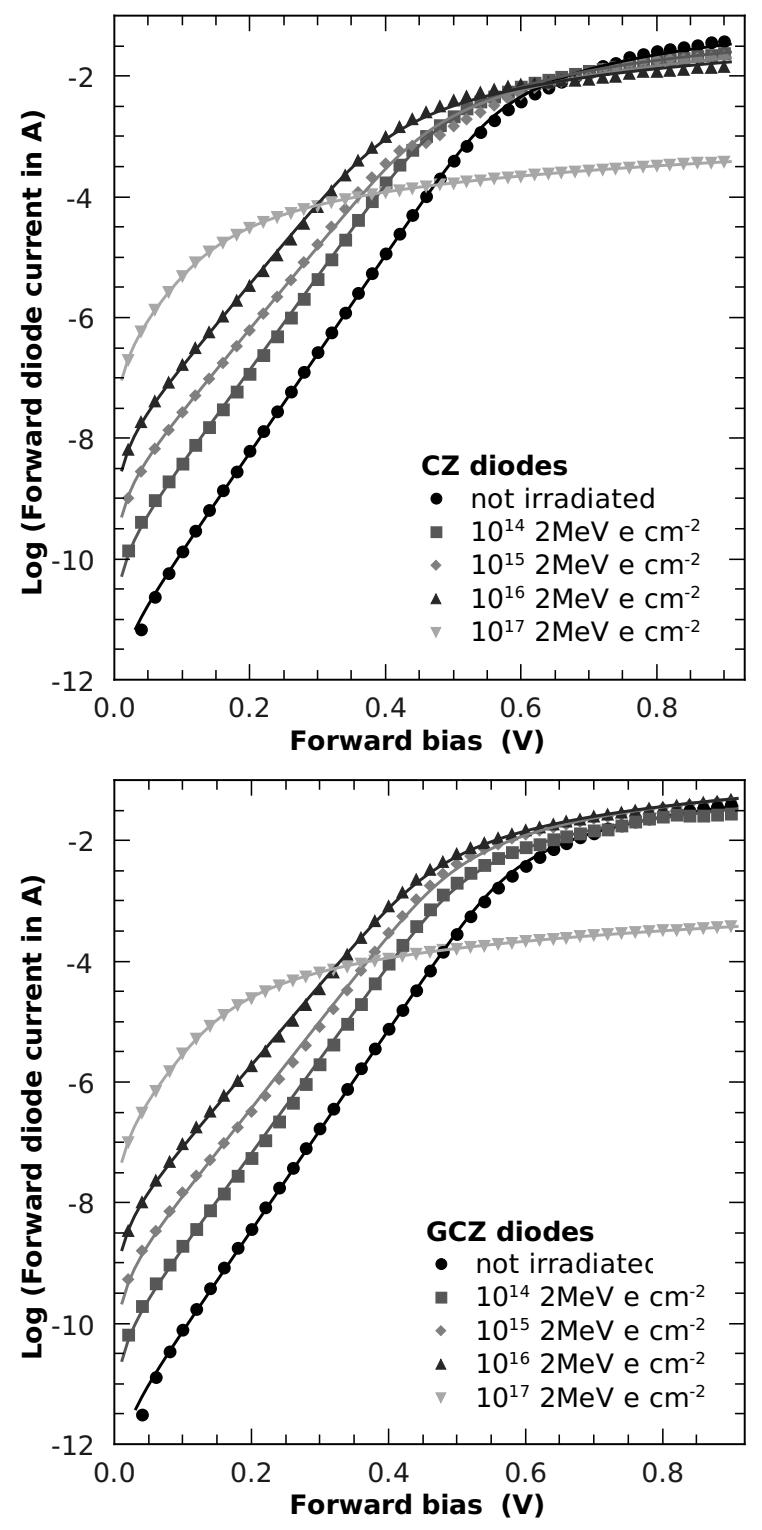

Figure 9: Forward characteristics of CZ (top) and GCZ (bottom) diodes before and after irradiation. The lines are the best fits using (6) and the resulting values of the fit parameters are listed in Table 3. 


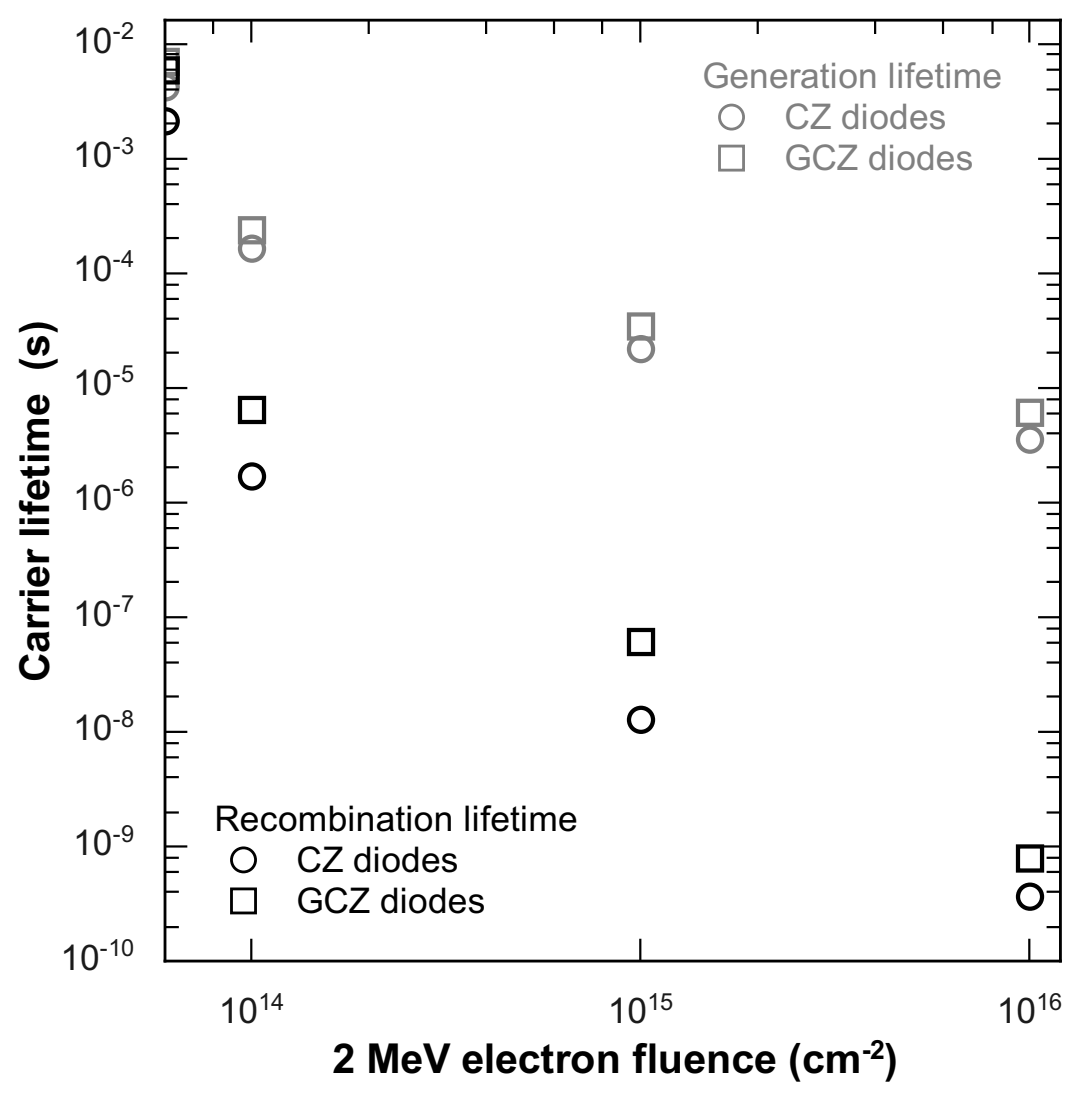

Figure 10: Minority carrier recombination and generation lifetime as derived from the forward and reverse diode characteristics, respectively. The data points on the y-axis are the values before electron irradiation. 